\title{
SOCS1 Mutation Subtypes Predict Divergent Outcomes in Diffuse Large B-Cell Lymphoma (DLBCL) Patients
}

\author{
Birgit Schif ${ }^{1,}{ }^{*}$, Jochen K. Lennerz ${ }^{1, *}$, Christian W. Kohler ${ }^{2}$, Stefan Bentink ${ }^{2}$, Markus \\ Kreuz ${ }^{3}$, Ingo Melzner ${ }^{1}$, Olga Ritz ${ }^{1}$, Lorenz Trümper $^{4}$, Markus Loeffler ${ }^{3}$, Rainer \\ Spang ${ }^{2}$, and Peter Möller ${ }^{1}$ \\ ${ }^{1}$ Institute of Pathology, University of UIm, Germany \\ 2 Institute of Functional Genomics, University Regensburg, Germany \\ ${ }^{3}$ Institute for Medical Informatics, Statistics and Epidemiology, University of Leipzig, Germany \\ ${ }^{4}$ Department of Hematology and Oncology, Georg-August-University Göttingen, Germany \\ * denotes equal contribution \\ Correspondence to: Peter Möller, email: peter.moeller@uniklinik-ulm.de \\ Keywords: Lymphoma, DLBCL, SOCSI mutation
}

Received: December 07, 2012, Accepted: December 09, 2012, Published: December 09, 2012

Copyright: ( Schif et al. This is an open-access article distributed under the terms of the Creative Commons Attribution License, which permits unrestricted use, distribution, and reproduction in any medium, provided the original author and source are credited.

\section{ABSTRACT:}

Suppressor of cytokine signaling 1 (SOCS1) is frequently mutated in primary mediastinal and diffuse large B-cell lymphomas (DLBCL). Currently, the prognostic relevance of these mutations in DLBCL is unknown. To evaluate the value of the SOCS1 mutation status as a prognostic biomarker in DLBCL patients, we performed full-length SOCS1 sequencing in tumors of 154 comprehensively characterized DLBCL patients. We identified 90 SOCS1 mutations in $16 \%$ of lymphomas. With respect to molecular consequences of mutations, we defined two distinct subtypes: those with truncating (major) and those with non-truncating mutations (minor), respectively. The SOCS1 mutated subgroup or the minor/major subtypes cannot be predicted on clinical grounds; however, assignment of four established gene-expression profilebased classifiers revealed significant associations of SOCS1 major cases with germinal center and specific pathway activation pattern signatures. Above all, SOCS1 major cases have an excellent overall survival, even better than the GCB-like subgroup. SOCS1 minor cases had a dismal survival, even worse than the ABC gene signature group. The SOCS1 mutation subsets retained prognostic significance in uni- and multivariate analyses. Together our data indicate that assessment of the SOCS1 mutation status is a single gene prognostic biomarker in DLBCL.

\section{INTRODUCTION}

Diffuse large B-cell lymphoma (DLBCL) is a heterogeneous group of rapidly growing neoplasms with an aggressive clinical course. An intensive multiagent chemotherapy can cure $\sim 40 \%$ of patients and the combination with anti-CD20 therapy has further improved outcome for additional $10-25 \%$ of patients [14]. Despite the marked progress in treatment response of DLBCL, $30 \%$ of patients remain with refractory, often incurable disease [2,5]. The variability in DLBCL outcome raises the question how one can identify these patient subsets. Currently, only few prognostic models that predict outcomes based on clinical data have been proposed [6,7]. Tissue-based classification schemes $[8,9]$ take expression of distinct proteins into account to predict clinical course and treatment response in DLBCL patients; however, these do not adequately reflect the heterogeneity of DLBCL. To get a handle on the diversity of DLBCL several gene expression based classifiers have been devised [10-13]. The most widely used molecular subclassification [10] divides DLBCL into at least three prognostic relevant subtypes: one clinically aggressive subset that demonstrates a profile similar to activated peripheral blood B-cells (ABC), a second subtype with a better prognosis that is similar to normal germinal center 
B-cells (GCB), and a third subtype, referred to as PMBL [14] with an outcome that is superior to all other DLBCL subtypes $[15,16]$. While gene expression profiling can help to refine DLBCL classification into GCB, ABC, and PMBL subtypes with survival differences in patients [17], its use in clinical practice is not yet routine.

Suppressor of cytokine signaling 1 (SOCS1) is frequently mutated in PMBL [18] and other lymphomas [19]. SOCS1 inhibits janus kinase (JAK)/signal transducer and activator of transcription (STAT) signaling [20]. The C-terminal domain including the SOCS box is necessary for this function [21] and we have shown that mutations affecting this domain result in abnormal stabilization of JAK2 and dysregulation of JAK/STAT signaling [18]. Although the specific role in lymphomagenesis remains to be elucidated, SOCS1 is a postulated tumor suppressor gene that is frequently inactivated by genomic mutations $[22,20]$. In case series and DLBCL cell lines, other groups have described SOCS1 mutations [23-25]; however, the prognostic relevance of SOCS1 mutations in DLBCL has not been addressed.

The aim of the present study was to assess the value of the SOCS1 mutation status as a prognostic biomarker in a well-characterized cohort of DLBCL patients. We found that SOCS1 mutation subtypes disclose significant differences in outcome. Thereby, assessment of the SOCS1 mutation status represents a novel tumor-derived, single gene prognostic biomarker in DLBCL.

\section{RESULTS}

SOCS1 mutations in DLBCL are frequent and do not cluster at mutational hotspots. Full-length sequencing of SOCS1 revealed mutations in $24(16 \%)$ of the 154 DLBCL samples (Table 1). Figure 1 summarizes the position and types of all SOCS1 mutations within the coding region (detailed information in Supplemental Figure 1 and Supplemental Table 1). In total, we found 90 unique mutational events in these 24 individual cases (referred to as SOCS1 mutant). Five of 24 SOCS1 mutant cases carried a single mutation, whereas multiple mutations accumulated in the majority of cases. Mapping of the SOCS1 mutations over the coding region and comparison with annotated mutations in the COSMIC database (Figure 2) demonstrated that mutations are spread throughout the coding region (Figure 2B). Although some domains were more frequently affected (Supplemental Table 2), there were no mutational hotspots. Specifically, SOCS1 mutations in DLBCL mainly affected the region encoding the JAK domain and therein the kinase inhibitory region (KIR) and Src homology 2 (SH2) subdomains. In addition, we noted that mutations are rarely located primarily in C-terminal domains; however, when consequences of $\left(5^{\prime}\right)$ upstream mutations were taken into account (Figure 2C), the fraction of cases with predicted alterations in C-terminal domains increased substantially. The deleterious impact of truncations and/or frameshifts that alter longer stretches of the gene, affected in particular

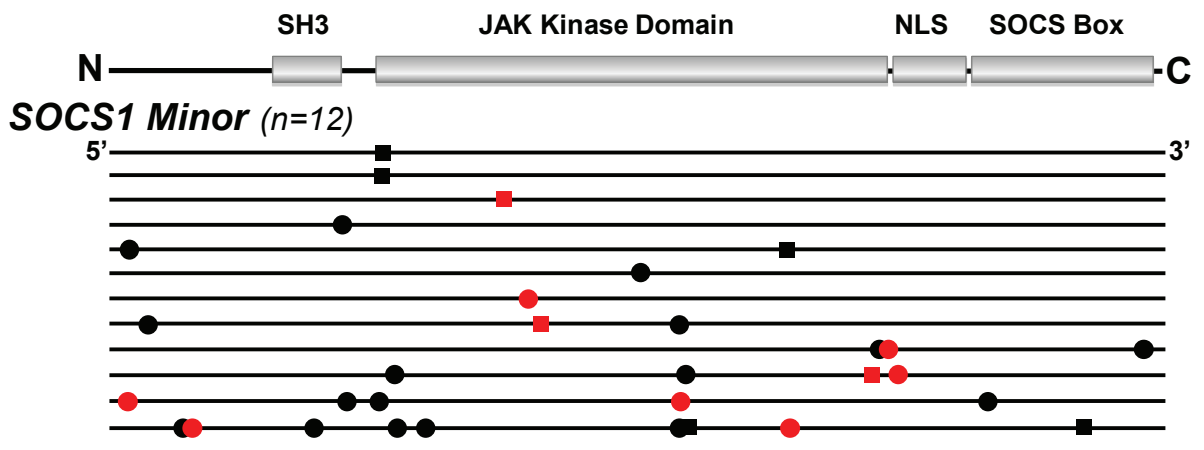

SOCS1 Major ( $n=12)$

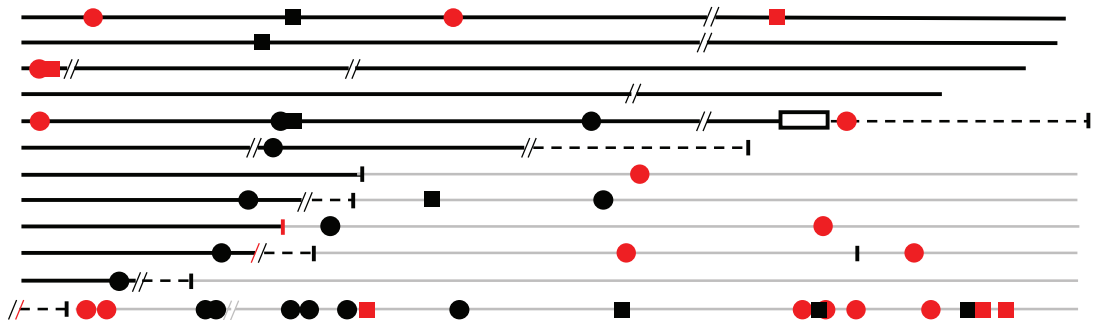

Figure 1: SOCS1 Mutations in DLBCL. SOCS1 sequences of mutated DLBCL plotted and sorted by number and predicted severity of mutations (top row, encoded domains over coding regions). SOCS1 coding region (length: 636bp) of each mutated samples is represented by a black line and symbols visualize the type and site of each mutation. Grey lines represent nonsense sequence after a mutation site, when appropriate. Circles are replacement substitutions, squares are silent mutations, diagonal lines are deletions, a box represents duplication, and vertical lines symbolize premature stop codons. Symbols are red when mutations occurred at consensus sites for somatic hypermutation. Note that SOCS1 mutations are randomly distributed within the coding region. Abbreviations: SH3, Src homology 3; JAK, Janus kinase; NLS, nuclear localization signal; SOCS box, silencer of cytokine signaling box. 
Table 1: Demographic and Clinical Characteristics of the Study Cohort screened for SOCS1 Mutations

\begin{tabular}{|c|c|c|}
\hline Characteristic & $\begin{array}{l}\text { Patient cohort } \\
\mathrm{n}=154\end{array}$ & $\%$ \\
\hline \multicolumn{3}{|l|}{ Age, years } \\
\hline Median (Range) & $64.5(3-93)$ & \\
\hline$<60$ years & 62 & 40.3 \\
\hline$\geq 60$ years & 92 & 59.7 \\
\hline \multicolumn{3}{|l|}{ Sex } \\
\hline Male & 92 & 59.7 \\
\hline Female & 62 & 40.3 \\
\hline \multicolumn{3}{|l|}{ Ann Arbor stage } \\
\hline I and II & 48 & 43.6 \\
\hline III and IV & 62 & 56.4 \\
\hline \multicolumn{3}{|l|}{ Lesions } \\
\hline EN only & 20 & 20 \\
\hline $\mathrm{N}$ only & 55 & 55 \\
\hline $\mathrm{EN}+\mathrm{N}$ & 25 & 25 \\
\hline \multicolumn{3}{|l|}{ B symptoms } \\
\hline Absent & 55 & 57.3 \\
\hline Present & 41 & 42.7 \\
\hline \multicolumn{3}{|l|}{ IPI-score* } \\
\hline 0 & 12 & 10.5 \\
\hline 1 & 49 & 43 \\
\hline 2 & 31 & 27.2 \\
\hline$>2$ & 22 & 19.3 \\
\hline \multicolumn{3}{|l|}{ Chemotherapy } \\
\hline ALL-like & 13 & 11.5 \\
\hline CHOP-like & 74 & 65.5 \\
\hline Other & 15 & 13.3 \\
\hline None & 11 & 9.7 \\
\hline \multicolumn{3}{|l|}{ Radiotherapy } \\
\hline No & 80 & 74.8 \\
\hline Yes & 27 & 25.2 \\
\hline \multicolumn{3}{|c|}{\begin{tabular}{|l|l|} 
Treatment response & \\
\end{tabular}} \\
\hline $\mathrm{CR}+\mathrm{CRu}$ & 54 & 60.0 \\
\hline $\mathrm{nC} / \mathrm{SD}$ & 2 & 2.2 \\
\hline PR & 15 & 16.7 \\
\hline PD & 19 & 21.1 \\
\hline \multicolumn{3}{|l|}{ Relapse } \\
\hline No & 104 & 86.0 \\
\hline Yes & 17 & 14.0 \\
\hline
\end{tabular}

Abbreviations: ALL, acute lymphoblastic leukemia; CHOP, cyclophosphamide, doxorubicin, vincristine and prednisolone; $\mathrm{CR}$, complete response; $\mathrm{CRu}$, complete response unconfirmed; EN, extranodal; n, total number; $\mathrm{N}$, nodal; nC/SD, no change/stable disease; PD, progressive disease; PR, partial response/resmission; IPI, international prognostic index. * for some patients not all IPI characteristics were available [i.e., a missing factor was set to "absent" (0); therefore some patients with IPI 0/1 may have higher IPI-scores; see supplemental figure 2E] the SOCS box (range $35-50 \%$ of SOCS1 mutant DLBCL). Thus, SOCS1 C-terminal domains are rarely affected by primary events; however, C-terminal domains are frequently mutated or lost due to more severe upstream mutations (detailed mutation frequencies are provided in Supplemental Table 2). Consequently, SOCS1 sequence analysis implies different degrees of mutational severity, which can be visualized via the length of intact coding sequence (Figure 1). Accordingly, we defined SOCS1 minor as cases that harbor only non-foreshortening point mutations (12 of 24 SOCS1 mutated cases in our cohort), and the SOCS1 major group as cases with truncating mutations or deletions that affect presence or position of C-terminal domains (12 of 24 SOCS1 mutated cases in our cohort; Figure 2C). To account for these differences, we performed subgroup analyses based on the two mutation subtypes (SOCS1 minor vs. major).

SOCS1 mutations preferentially occur at somatic hypermutation motifs. A previous study has postulated that SOCS1 mutations might be the result of somatic hypermutation [25]. We checked the hotspot consensus motifs (RGYW/WRCY, DGYW/WRCH and WA/TW) known as somatic hypermutation target sites that result in single nucleotide substitutions (for details see methods and supplement). The numbers of point mutations per case ranged from 1-18 (Supplemental Table 3) and accumulated in the somatic hypermutation motifs $(40,8$ $\%)$. G/C nucleotides $(n=64)$ were targeted more frequently compared to $\mathrm{A} / \mathrm{T}(\mathrm{n}=12)$ nucleotides ( 26 vs. 5 in somatic hypermutation motifs). In cases MPI-109 and MPI153 , one flanking region of each deletion was a somatic hypermutation site (Supplemental Figure 1, Supplemental Table 1). The frequency, location, and translational consequence of SOCS1 mutations in our data sustain the hypothesis that these mutations are caused by aberrant somatic hypermutation.

SOCS1 mutation status cannot be predicted on clinical grounds. Clinical characteristics of 154 DLBCL patients were analyzed with respect to their co-occurrence with SOCS1 mutations. Table 2 lists the clinical and pathological features of SOCS1 mutant DLBCL patients. The immunophenotype of SOCS1 mutant DLBCL was characterized by presence of BCL2 (18/24, 75.0\%) and BCL6 expression $(23 / 23,100.0 \%$ of evaluable cases). CD10 was expressed in 7 of $24(29.2 \%)$, and MUM1 in 12 of $22(54.5 \%$ of evaluable cases). Ki-67 immunostaining of SOCS1 mutant cases was variable but indicated a high proliferative rate. Seven of 23 cases (30.4\%) displayed a BCL6 breakpoint by FISH analysis. Furthermore, comparison of SOCS1 wild-type vs. SOCS1 mutation subtypes did not allow discrimination based on any specific clinicopathological feature (Table 3 ). In consequence, the SOCS1 status cannot be inferred from a basic panel of clinical parameters.

SOCS1 major mutations exhibit the GCB gene expression signature. We correlated four established gene 
expression classifications (COO, mBL, CC, PAP) with the presence of SOCS1 mutations (Table 4). Each expressionbased signature captures a different aspect of DLBCL biology that may track with the SOCS1 mutation status. The COO signature divided the 24 SOCS1 mutant cases into 19 (79.2\%) GCB-like lymphomas and 5 (20.8\%) nonGCB lymphomas. Strikingly, all 12 SOCS1 major cases show a GCB signature, whereas those with SOCS1 minor mutations showed no trend for a specific COO signature. SOCS1 mutation status was at least in this DLBCL cohort not associated with the mBL signature (Table 4). Additionally, SOCS1 mutations did not occur uniformly distributed over the PAP classification scheme $(P=0.003$; Fisher's exact test). Specifically, 12 SOCS1 mutant cases displayed the PAP-1 signature $[\mathrm{n}=12(32 \%)$ of all 37 PAP1 vs. $\mathrm{n}=12(10 \%)$ of all 117 non-PAP-1; $P=0.003]$. Further analysis by SOCS1 mutation subtype revealed that $58.3 \%$ of the SOCS1 major cases display the PAP-1 pattern. There was no specific association with any $\mathrm{CC}$ signature (i.e. OxPhos, BCR, HR) in SOCS1 mutant, SOCS1 major

A

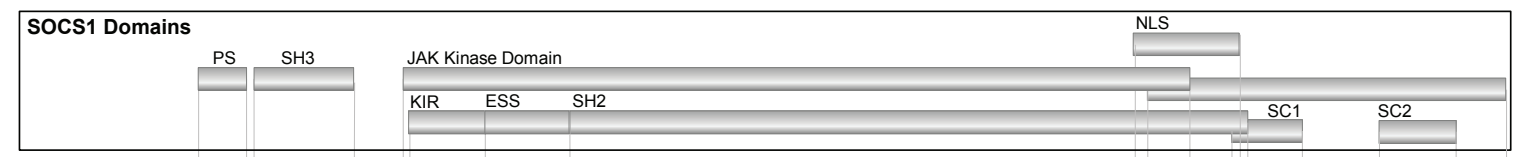

B

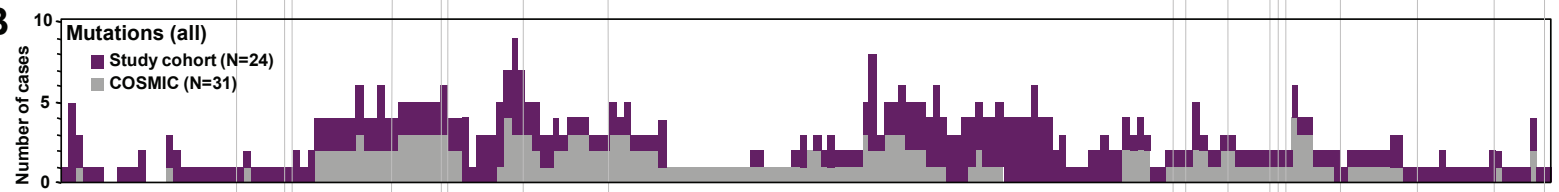

C

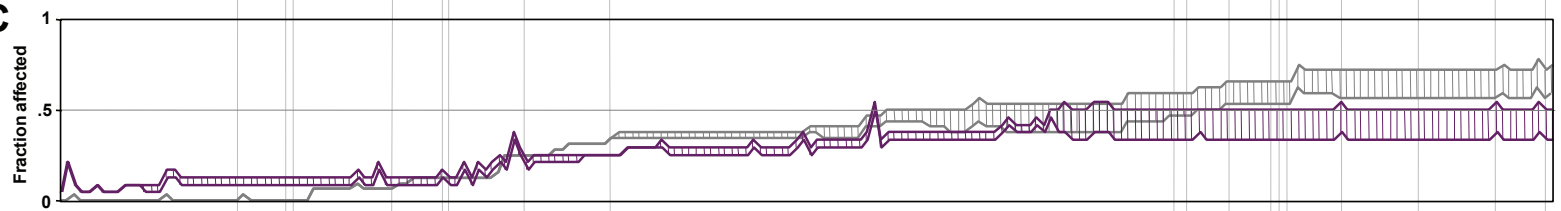

D

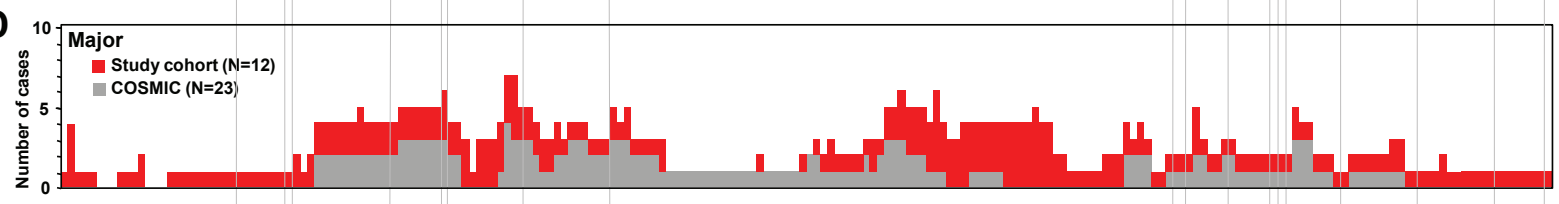

E

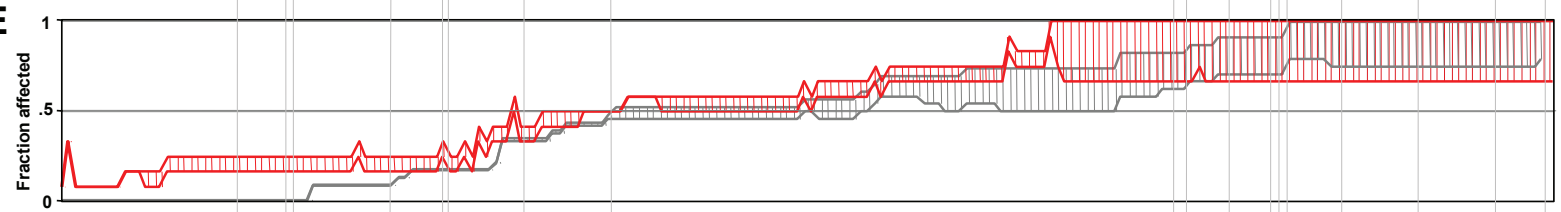

$\mathbf{F}$

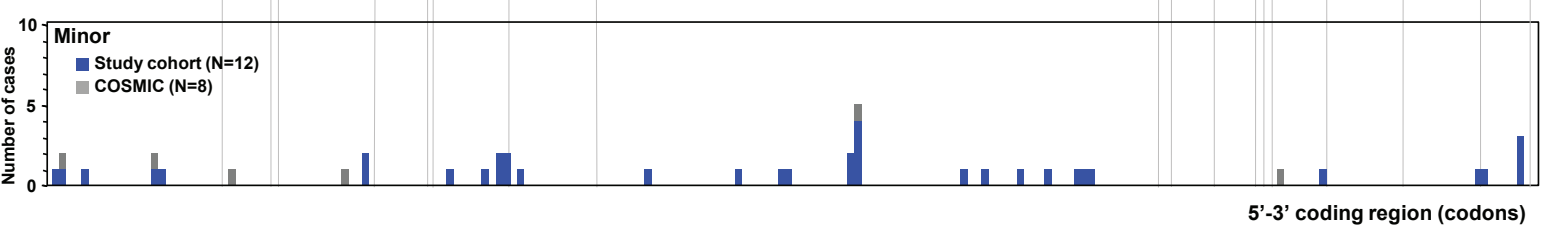

Figure 2: SOCS1 Mutation Frequency. A. SOCS1 coding region depicted as scheme of functional domains. B. Frequency map compares regional distribution of SOCS1 mutations in DLBCL cases from our cohort (purple bars, N=24) and all SOCS1 mutated cases form the COSMIC database (grey bars, $\mathrm{N}=31$ ); there are no mutational hotspots. While the KIR and SH2 regions within the JAK domain were frequently affected, mutations directly affecting the C-terminal SOCS box were rarely seen. C. Fraction of cases affected by downstream consequences of 5' mutations. The plot was constructed considering a range of predicted functional consequences of length-altering mutations (i.e., truncating and/or frameshift mutations) on downstream domains. The bottom line indicates a 'conservative' weighing where only the complete lack of C-terminally encoded domains is considered a deleterious event whereas in the top line, a more 'aggressive' weighing also accounted for alterations in domain position or partial disruptions of domains. Thus, the range between lines symbolizes the predicted spectrum of encoded downstream consequences of 5' mutations. Shown is a comparison of our study cohort (purple) and the COSMIC database (grey). Based on these graphs, cases with truncating or deleterious mutations that affected presence or position of C-terminal domains were considered SOCS1 major whereas those cases with non-truncating/non-foreshortening mutations (i.e., point mutations) were considered SOCS1 minor. D. Subgroup analysis of regional distribution of SOCS1 major mutations in our DLBCL cohort (red; $\mathrm{N}=12$ ) in comparison to major cases in the COSMIC database (grey; $\mathrm{N}=23$ ). Note the absence of mutational hotspots. E. Fraction of 5' C-terminal consequences in SOCS1 major subgroup in our cohort (red) and in the COSMIC database (grey). F. Fraction of mutations in the SOCS1 minor subgroups in our cohort (blue, N=12) and the COSMIC database (grey, $\mathrm{N}=3$ ). 
or SOCS1 minor DLBCL cases. Together, examination of four established expression signatures revealed that SOCS1 mutant cases and in particular SOCS1 major cases accumulate in GCB and PAP-1 lymphomas. Notably, all SOCS1 major cases harbored the GCB signature.

SOCS1 major and minor mutated cases differ in clinical outcome. At the time of data evaluation, clinical follow up information was available for 122 of 154 patients ( $\sim 80 \%$ of the cohort). The median followup time of patients was 21.8 months (1.7 years; range: $0-22.3$ years). Seventy-eight patients had died of disease $(\sim 51 \%)$ and 46 patients were either alive or lost to followup (censored). Based on combination chemotherapy carried out in the pre-rituximab era, the patients were not uniformly treated (Table 1) $[11,26]$. There was no difference in overall survival between SOCS1 mutant and SOCS1 wild-type cases (Figure 3A, $P=0.45$ ). Interestingly, the subgroups SOCS1 major and SOCS1 minor showed marked survival differences to SOCS1 wild-type patients, however, in different directions: While overall survival was longer in patients with lymphomas that harbor SOCS1 major mutations, it was shorter in patients with SOCS1 minor mutations (Figure 3A). For quantitative comparison of prognostic effects, we determined the log hazard ratios using univariate Cox proportional hazard regression models (Figure 4A). In line with Figure 3, we observed that SOCS1 gene mutation status by itself has little prognostic impact; however, SOCS1 mutation subtypes herald different prognostic fates. More importantly, the comparison of hazard ratios across prognostic predictors showed that the SOCS1 status is a strong factor. It is due to these strong effects that the SOCS1 status reached statistical significance in spite of the relatively small number of cases in these two subgroups.

Patients with GCB-like lymphomas have a better prognosis than those with ABC-like lymphomas [10]. Notably, all our SOCS1 major cases were of the GCBlike type, suggesting that this might explain the survival difference. We plotted Kaplan-Meier curves for overall survival of SOCS1 major and SOCS1 minor against the SOCS1 wild-type subgroup that we additionally separated into GCB- and ABC subgroups (Figure 3B). These curves suggest that SOCS1 major cases carry a good prognosis also when compared to GCB-SOCS1 wild-type cases only, whereas SOCS1 minor cases have a poor prognosis even when compared to ABC-SOCS1 wild-type cases. Moreover, the prognostic value of the COO signature remains intact when reduced to SOCS1 wild-type cases suggesting that it cannot be attributed to the SOCS1 mutation status alone. We corroborated this observation in a multivariate Cox model. With respect to outcome, the SOCS1 mutation status had significant prognostic information independent of the covariates age, AAS, and COO signature (Figure 4B). Together these analyses demonstrated that SOCS1 major status is a predictor for better survival whereas SOCS1 minor status is a predictor for worse survival.

\section{DISCUSSION}

Here, we evaluated the prognostic value and molecular characteristics of SOCS1 mutations in a well-characterized cohort of 154 DLBCL patients. We show that SOCS1 mutational subtypes are associated with divergent outcomes as well as distinct expression signatures. Thereby, SOCS1 mutation status is a novel tumor-derived, single gene biomarker with molecular and prognostic implications in DLBCL.

Full-length SOCS1 sequencing revealed 90 mutations in 24 of 154 DLBCL cases (16\%), which is in line with SOCS1 mutation frequencies in smaller DLBCL series (7/26 [25] and 8/33 [24]). Recently, two groups reported genome-wide mutation analyses of DLBCL with highly concordant results $[23,27]$. Remarkably, wholeexome sequencing disclosed SOCS1 gene mutations in three DLBCL patients [23]. Here, we observed the accumulation of single nucleotide substitutions at sites preferentially targeted by somatic hypermutation. Given that frequencies and patterns are compatible with other hypermutated genes [28], our findings support the notion that germinal-center experienced lymphomas are prone to acquire SOCS1 gene mutations by somatic hypermutation [25]. This conclusion has recently been confirmed using genome-wide approaches [29]. In addition, the spread of mutations over the coding region sustains the hypothesis that SOCS1 is a tumor suppressor [20].

From a clinical perspective, our key finding is that the prognosis of patients with SOCS1 mutations strongly depends on the nature of the mutation. We organized mutations by the lengths of intact encoded sequence (Figure 1,2), thus splitting the cases in two groups: SOCS1 major, which has a good prognosis and SOCS1 minor, which has a poor prognosis (Figure 3,4). While these findings are promising, several aspects should be taken into account: First, despite being the largest SOCS1 mutation study in DLBCL to date, the number of cases in mutated subgroups is relatively small. While this is a typical side effect of highly resolved molecular stratifications, the estimated hazard ratios were so large that the survival difference reached statistical significance both in uni- and multivariate analyses (Figure 4). Second, determination whether a specific mutation was mono- or biallelic was precluded due to the presence of varying amounts of nonneoplastic cells in the tumor samples. This biologically imposed limitation should however not lessen the value of the biomarker and rather simplify the implementation process in terms of ease of diagnostic assessment. Third, we are not able to provide a specific biological explanation for the observed prognostic differences in the SOCS1 mutation subgroups. It is tempting to hypothesize that the more severe, truncating mutations as seen in the SOCS1 major cases result in loss of its inhibitory function (i.e., 
Table 2: Clinicopathological Characteristics of Cases with SOCS1 Mutations

\begin{tabular}{|c|c|c|c|c|c|c|c|c|c|c|c|c|c|c|}
\hline \multirow[t]{2}{*}{ ID } & \multirow{2}{*}{$\begin{array}{l}\text { Age, } \\
\text { Sex } \\
\end{array}$} & \multirow{2}{*}{$\begin{array}{l}\text { DLBCL } \\
\text { Subtype* }^{*}\end{array}$} & \multicolumn{5}{|c|}{ Immunohistochemistry } & \multicolumn{3}{|c|}{ FISH } & \multicolumn{4}{|c|}{ Gene Expression Signatures } \\
\hline & & & CD10 & BCL2 & BCL6 & MUM1 & Ki-67 & MYC & BCL6 & $\mathrm{t}(14 ; 18)$ & $\mathrm{COO}$ & $\mathrm{mBL}$ & PAP & $\mathrm{CC}$ \\
\hline $\begin{array}{l}\text { MPI- } \\
135\end{array}$ & $77, \mathrm{~F}$ & ANA & - & + & + & + & 99 & - & - & - & $\mathrm{ABC}$ & non-mBL & PAP-3 & BCR \\
\hline $\begin{array}{l}\text { MPI- } \\
202\end{array}$ & $72, \mathrm{M}$ & NOS & - & - & + & + & 80 & - & + & - & GCB & non-mBL & PAP-1 & HR \\
\hline $\begin{array}{l}\text { MPI- } \\
166\end{array}$ & $54, \mathrm{M}$ & NOS & + & + & + & + & 30 & - & - & + & GCB & non-mBL & mind-L & BCR \\
\hline $\begin{array}{l}\text { MPI- } \\
247\end{array}$ & $70, \mathrm{M}$ & $\mathrm{CB}$ & - & + & + & + & 90 & - & + & - & un. & non-mBL & PAP-1 & BCR \\
\hline $\begin{array}{l}\text { MPI- } \\
030\end{array}$ & $59, \mathrm{M}$ & $\mathrm{CB}$ & - & + & + & + & 60 & - & - & - & GCB & non-mBL & PAP-1 & HR \\
\hline $\begin{array}{l}\text { MPI- } \\
165\end{array}$ & $86, \mathrm{~F}$ & NOS & - & - & + & - & 95 & nIG & + & - & GCB & Intermed & mind-L & BCR \\
\hline $\begin{array}{l}\text { MPI- } \\
199\end{array}$ & $66, \mathrm{M}$ & $\mathrm{CB}$ & - & + & + & + & 50 & - & - & - & $\mathrm{ABC}$ & non-mBL & PAP-1 & HR \\
\hline $\begin{array}{l}\text { MPI- } \\
063\end{array}$ & $73, \mathrm{~F}$ & NOS & - & + & + & + & NA & - & NA & - & un. & non-mBL & PAP-3 & OxP \\
\hline $\begin{array}{l}\text { MPI- } \\
092\end{array}$ & $58, \mathrm{~F}$ & $\mathrm{CB}$ & - & + & + & + & 65 & - & - & - & GCB & non-mBL & mind-L & OxP \\
\hline \begin{tabular}{l|} 
MPI- \\
157
\end{tabular} & $40, \mathrm{M}$ & NOS & - & + & + & - & 45 & - & + & - & un. & non-mBL & PAP-2 & NA \\
\hline $\begin{array}{l}\text { MPI- } \\
046\end{array}$ & $59, \mathrm{~F}$ & NOS & + & + & + & - & 80 & nIG & - & + & GCB & Intermed & PAP-3 & BCR \\
\hline $\begin{array}{l}\text { MPI- } \\
134\end{array}$ & $29, \mathrm{~F}$ & CB & - & - & + & + & 85 & - & - & - & GCB & non-mBL & PAP-1 & HR \\
\hline $\begin{array}{l}\text { MPI- } \\
105\end{array}$ & $60, \mathrm{~F}$ & $\mathrm{CB}$ & - & + & + & - & 75 & - & + & - & GCB & non-mBL & PAP-1 & HR \\
\hline $\begin{array}{l}\text { MPI- } \\
241\end{array}$ & $40, \mathrm{~F}$ & NOS & - & + & + & - & 80 & - & + & - & GCB & non-mBL & mind-L & BCR \\
\hline $\begin{array}{l}\text { MPI- } \\
122\end{array}$ & $18, \mathrm{M}$ & $\mathrm{CB}$ & - & + & + & + & 90 & - & - & - & GCB & non-mBL & PAP-1 & HR \\
\hline $\begin{array}{l}\text { MPI- } \\
220\end{array}$ & $65, \mathrm{~F}$ & NOS & + & + & + & NA & 90 & IG & - & - & GCB & $\mathrm{mBL}$ & mind-L & NA \\
\hline $\begin{array}{l}\text { MPI- } \\
248\end{array}$ & $56, \mathrm{M}$ & IB & + & + & + & - & 50 & nIG & - & + & GCB & Intermed & mind-L & BCR \\
\hline \begin{tabular}{l|} 
MPI- \\
136 \\
\end{tabular} & $32, \mathrm{M}$ & $\mathrm{CB}$ & - & + & + & - & 95 & - & - & - & GCB & non-mBL & PAP-1 & HR \\
\hline $\begin{array}{l}\text { MPI- } \\
137\end{array}$ & $18, \mathrm{M}$ & NOS & - & + & + & + & 85 & - & - & - & GCB & non-mBL & PAP-1 & NA \\
\hline $\begin{array}{l}\text { MPI- } \\
207\end{array}$ & $27, \mathrm{M}$ & NOS & - & - & + & + & 70 & - & - & - & GCB & non-mBL & PAP-1 & HR \\
\hline $\begin{array}{l}\text { MPI- } \\
036\end{array}$ & $70, \mathrm{~F}$ & $\mathrm{CB}$ & + & + & + & - & 98 & IG & - & + & GCB & Intermed & mind-L & BCR \\
\hline $\begin{array}{l}\text { MPI- } \\
153\end{array}$ & $78, \mathrm{~F}$ & $\mathrm{CB}$ & - & - & NA & NA & 50 & - & + & - & GCB & non-mBL & PAP-1 & BCR \\
\hline $\begin{array}{l}\text { MPI- } \\
102\end{array}$ & $21, \mathrm{~F}$ & NOS & + & + & + & - & 80 & nIG & - & - & GCB & non-mBL & PAP-1 & NA \\
\hline $\begin{array}{l}\text { MPI- } \\
109\end{array}$ & $42, \mathrm{M}$ & $\mathrm{CB}$ & + & - & + & - & 75 & - & - & - & GCB & non-mBL & PAP-4 & BCR \\
\hline
\end{tabular}

Abbreviations: ABC, activated B cell; ANA, anaplastic; $\mathrm{CB}$, centroblastic; $\mathrm{CC}$, consensus cluster signature; $\mathrm{COO}$, cell-of-origin signature; DLBCL, diffuse large B-cell lymphoma; F, female; FISH, fluorescence in situ hybridisation; GCB, germinal center B cell; HR, host-response; IB, immunoblastic; ID, MPI-number from MMML cohort [11]; IG, immunoglobulin rearrangement of $M Y C$ gene; Intermed., intermediate signature; Ki-67, proliferation index in percent; M, male; mBL, molecular-Burkitt signature; mind-L, molecularly individual lymphoma; NA, not available; nIG, non-IG type of MYCrearrangement; NOS, DLBCL not otherwise specified; OxPhos, oxidative-phosphorylative pathway; PAP, pathway activation pattern signature; $\mathrm{t}(14 ; 18)$, BCL2-IGH translocation; un., unclassified; cut-offs for BCL2-, BCL6- and MUM1-negativity by immunohistochemistry were $\leq 25 \%$ and $0 \%$ for CD10negativity. *according to Hummel et al [11]. 
Table 3: Clinical Characteristics of Patient Subsets based on SOCS1 Status

\begin{tabular}{|c|c|c|c|c|c|c|c|c|c|c|c|}
\hline \multirow{2}{*}{\begin{tabular}{|l|} 
\\
Characteristic
\end{tabular}} & \multicolumn{2}{|c|}{$\begin{array}{c}\text { WT } \\
(n=130)\end{array}$} & \multicolumn{2}{|c|}{$\begin{array}{c}\text { SOCS1 Mut. } \\
(\mathrm{n}=24)\end{array}$} & \multicolumn{2}{|c|}{$\begin{array}{c}\text { SOCS1 Maj. } \\
(\mathrm{n}=12)\end{array}$} & \multicolumn{2}{|c|}{$\begin{array}{c}\text { SOCS1 Min. } \\
(\mathrm{n}=12)\end{array}$} & \multirow{2}{*}{\begin{tabular}{|c|}
$P$ \\
WT \\
vs. \\
Mut.
\end{tabular}} & \multirow{2}{*}{\begin{tabular}{|c|} 
P \\
WT \\
vs. \\
Maj.
\end{tabular}} & \multirow{2}{*}{\begin{tabular}{|c|}
$P$ \\
WT \\
vs. \\
Min.
\end{tabular}} \\
\hline & No. & $\%$ & No. & $\%$ & No. & $\%$ & No. & $\%$ & & & \\
\hline \multicolumn{12}{|l|}{ Age, years } \\
\hline Median(Range) & \multicolumn{2}{|c|}{$66,0(3-93)$} & \multicolumn{2}{|c|}{$58.5(18-86)$} & \multicolumn{2}{|c|}{$56.5(18-78)$} & \multicolumn{2}{|c|}{$62.5(29-86)$} & 0.46 & 0.13 & 0.66 \\
\hline$<60$ & 48 & 36.9 & 14 & 58.3 & 8 & 66.7 & 6 & 50 & 0.07 & 0.06 & 0.37 \\
\hline$\geq 60$ & 82 & 63.1 & 10 & 41.7 & 4 & 33.3 & 6 & 50 & & & \\
\hline Sex & & & & & & & & & 0.37 & 0.54 & 0.54 \\
\hline Male & 80 & 61.5 & 12 & 50 & 6 & 50 & 6 & 50 & & & \\
\hline Female & 50 & 38.5 & 12 & 50 & 6 & 50 & 6 & 50 & & & \\
\hline Ann Arbor stage & & & & & & & & & 1.0 & 1.0 & 1.0 \\
\hline I and II & 41 & 44.1 & 7 & 41.2 & 4 & 44.4 & 3 & 37.5 & & & \\
\hline III and IV & 52 & 55.9 & 10 & 58.8 & 5 & 55.6 & 5 & 62.5 & & & \\
\hline Lesions & & & & & & & & & 0.73 & 0.91 & 0.75 \\
\hline EN only & 16 & 18.9 & 4 & 26.7 & 2 & 25 & 2 & 28.6 & & & \\
\hline $\mathrm{N}$ only & 48 & 56.5 & 7 & 46.6 & 4 & 50 & 3 & 42.9 & & & \\
\hline $\mathrm{EN}+\mathrm{N}$ & 21 & 24.7 & 4 & 26.7 & 2 & 25 & 2 & 28.6 & & & \\
\hline B symptoms & & & & & & & & & 0.40 & 0.28 & 1 \\
\hline Absent & 48 & 59.3 & 7 & 53.8 & 3 & 37.5 & 4 & 57.1 & & & \\
\hline Present & 33 & 40.7 & 8 & 61.5 & 5 & 62.5 & 3 & 42.9 & & & \\
\hline IPI-factors & & & & & & & & & 0.79 & 0.5 & 1 \\
\hline 0,1 & 51 & 51.5 & 10 & 58.8 & 6 & 66.6 & 4 & 50 & & & \\
\hline$\geq 2$ & 46 & 46.5 & 7 & 41.2 & 3 & 33.3 & 4 & 50 & & & \\
\hline Chemotherapy & & & & & & & & & 0.11 & 0.48 & 0.49 \\
\hline ALL-like & 12 & 12.8 & 1 & 5.3 & 1 & 11.1 & - & - & & & \\
\hline CHOP-like & 59 & 62.8 & 15 & 78.9 & 7 & 77.8 & 8 & 80 & & & \\
\hline Other & 13 & 13.8 & 2 & 10.5 & 1 & 11.1 & 1 & 10 & & & \\
\hline None & 10 & 10.6 & 1 & 5.3 & - & - & 1 & 10 & & & \\
\hline Radiotherapy & & & & & & & & & 1 & 0.24 & 0.44 \\
\hline \begin{tabular}{|l|} 
No \\
\end{tabular} & 66 & 75 & 14 & 73.7 & 5 & 55.6 & 9 & 90 & & & \\
\hline Yes & 22 & 25 & 5 & 26.3 & 4 & 44.4 & 1 & 10 & & & \\
\hline $\begin{array}{l}\text { Treatment } \\
\text { response }\end{array}$ & & & & & & & & & 0.78 & 0.47 & 0.65 \\
\hline $\mathrm{CR}$ & 36 & 47.4 & 7 & 50.0 & 6 & 66.7 & 1 & 20 & & & \\
\hline $\mathrm{CR}$, unconfirmed & 9 & 11.8 & 2 & 14.3 & 1 & 11.1 & 1 & 20 & & & \\
\hline $\mathrm{nC} / \mathrm{SD}$ & 2 & 2.6 & - & - & - & - & - & - & & & \\
\hline PR & 13 & 17.1 & 2 & 14.3 & 1 & 11.1 & 1 & 20 & & & \\
\hline PD & 16 & 21.1 & 3 & 21.4 & 1 & 11.1 & 2 & 40 & & & \\
\hline Relapse & & & & & & & & & 0.74 & 1.0 & 1.0 \\
\hline No & 86 & 85.1 & 18 & 90 & 9 & 90 & 9 & 90 & & & \\
\hline Yes & 15 & 14.9 & 2 & 10 & 1 & 10 & 1 & 10 & & & \\
\hline
\end{tabular}

Abbreviations: ALL, acute lymphoblastic leukemia; CHOP, cyclophosphamide, doxorubicin, vincristine and prednisolone; CR, complete response; EN, extranodal; IPI, international prognostic index; Maj., major; Min.; minor; Mut., mutant; n, total number; N, nodal; nC, no change; No., number of cases; PD, progressive disease; PR, partial response; SD, stable disease; $W T$, wild-type; $P$ values refer to Fisher's exact test (including all characteristics except in chemotherapy: CHOP-like vs. non-CHOP and in treatment response $\mathrm{CR} / \mathrm{CR}$, unconfirmed vs. $\mathrm{nC} / \mathrm{SD} / \mathrm{PR} / \mathrm{PD})$. 
resulting in prolonged activation of JAK/STAT signaling). For example, from SOCS1 major mutated cell lines we know that this is the case $[18,22]$. However, one has to acknowledge that the prognostic differences are not necessarily a linear consequence of the underlying molecular pathology and clearly not of the natural course of the disease. Rather, we observe a composite effect that includes at least chemotherapy-induced alterations as well as variability in response to treatment. To guide the design and interpretation of future functional studies, we abstain from speculations and merely point out that
SOCS1 major vs. SOCS1 minor mutations are associated with increased vs. reduced overall survival, respectively. Fourth, the retrospective nature of this study does not account for treatment advances achieved by rituximab [3]. Interestingly, to date the majority of established prognostic factors in DLBCL remained prognostic - also in R-CHOP based studies [1]. Therefore, the strength of the observed associations between SOCS1 mutation subtypes and overall survival makes SOCS1 sequence analysis a promising prognostic biomarker candidate in DLBCL. Finally, the lack of mutational hotspots requires
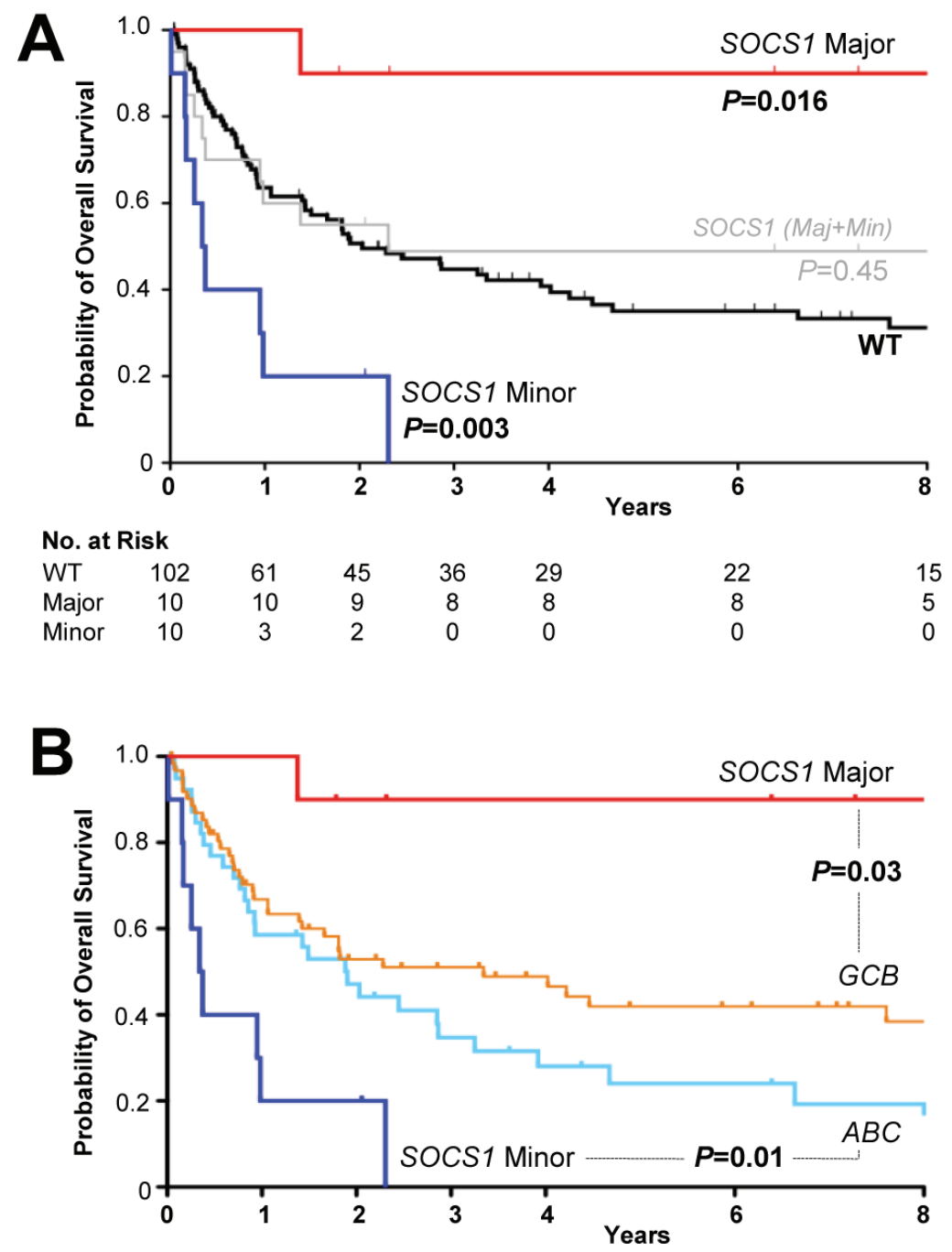

\begin{tabular}{lccccccc}
\multicolumn{2}{l}{ No. at Risk } \\
Major & 10 & 10 & 9 & 8 & 8 & 8 & 5 \\
GCB & 62 & 39 & 29 & 25 & 21 & 16 & 11 \\
ABC & 40 & 22 & 15 & 11 & 8 & 6 & 4 \\
Minor & 10 & 3 & 2 & 0 & 0 & 0 & 0
\end{tabular}

Figure 3: Kaplan-Meier Survival Estimates According to SOCS1 Mutation Status. A. The presence of SOCS1 mutations (grey) in DLBCL patients was not associated with different overall survival compared to SOCS1 wild-type (black; $=0.45$ ). Overall survival among patients with tumors harboring SOCS1 major mutations (red) was better when compared with SOCS1 wild-type ( $P=0.016)$. DLBCL cases with SOCS1 minor mutations (blue) had a poor overall survival when compared to $S O C S 1$ wild-type cases $(P=0.003)$. B. Relationship of overall survival according to SOCS1 mutation type and cell-of-origin expression signature. Clinical outcome of SOCS1 major patients (red line) differed significantly from patients with a GCB signature (orange line; $P=0.03$ ). Clinical outcome of patients with $S O C S 1$ minor patients (dark blue line) was significantly worse when compared to patients with an $\mathrm{ABC}$ signature (light blue line; $P=0.01$ ). All $P$ values from Cox regression models. 
Table 4: Gene-Expression Signatures of Patient Subsets based on SOCS1 Status.

\begin{tabular}{|l|l|l|l|l|l|l|l|l|l|l|l|l|}
\hline & \multicolumn{2}{l}{ WT } & \multicolumn{3}{l}{ SOCS1 Mut. } & SOCS1 Major & SOCS1 Minor & P & $P$ & P \\
\hline Signatures & No. & $\%$ & No. & $\%$ & No. & $\%$ & No. & $\%$ & $\begin{array}{l}\text { WT vs. } \\
\text { Mut. }\end{array}$ & $\begin{array}{l}\text { WT } \\
\text { Maj. }\end{array}$ & $\begin{array}{l}\text { WT } \\
\text { Min. }\end{array}$ \\
\hline COO & & & & & & & & & 0.0006 & $<0.001$ & 0.23 \\
\hline GCB & 51 & 39.2 & 19 & 79.2 & 12 & 100 & 7 & 58.3 & & & \\
\hline ABC & 47 & 36.2 & 2 & 8.3 & - & - & 2 & 16.7 & & & \\
\hline Uncl. & 32 & 24.6 & 3 & 12.5 & - & - & 3 & 25 & & & \\
\hline mBL & & & & & & & & & 1 & 0.6 & 1 \\
\hline mBL & 9 & 6.9 & 1 & 4.2 & 1 & 8.3 & - & - & & & \\
\hline non-mBL & 90 & 69.2 & 19 & 79.2 & 9 & 75 & 10 & 83.3 & & & \\
\hline Interm. & 31 & 23.8 & 4 & 16.7 & 2 & 16.7 & 2 & 16.7 & & & \\
\hline CC & & & & & & & & & 0.81 & 1 & 0.75 \\
\hline BCR & 66 & 55.0 & 10 & 50.0 & 5 & 56 & 5 & 45.5 & & & \\
\hline HR & 38 & 31.7 & 8 & 40.0 & 4 & 44 & 4 & 36.4 & & & \\
\hline OxPhos & 16 & 13.3 & 2 & 10.0 & - & - & 2 & 18.2 & & & \\
\hline PAP & & & & & & & & & 0.003 & 0.006 & 0.13 \\
\hline BL-PAP & 10 & 7.7 & - & - & - & - & - & - & & & \\
\hline Mind-L & 38 & 29.2 & 7 & 29.2 & 4 & 33.3 & 3 & 25 & & & \\
\hline PAP-1 & 25 & 19.2 & 12 & 50.0 & 7 & 58.3 & 5 & 41.7 & & & \\
\hline PAP-2 & 27 & 20.8 & 1 & 4.2 & - & - & 1 & 8.3 & & & \\
\hline PAP-3 & 21 & 16.2 & 3 & 12.5 & - & - & 3 & 25 & & & \\
\hline PAP-4 & 9 & 6.9 & 1 & 4.2 & 1 & 8.3 & - & - & & & \\
\hline
\end{tabular}

Abbreviations: $\mathrm{ABC}$, activated $\mathrm{B}$ cell; $\mathrm{BCR}, \mathrm{B}$ cell receptor and activation; BL-PAP, Burkitt lymphomapathway activation pattern; $\mathrm{CC}$, consensus cluster; $\mathrm{COO}$, cell-of-origin signature; $\mathrm{GCB}$, geminal center B-cell; Interm., intermediate; HR, host-response; mBL, molecular Burkitt lymphoma defined as $95 \%$ similar to Burkitt lymphoma [11]; Mind-L, molecularly individual lymphoma; Mut., mutant; No., number of cases; Uncl., unclassified; non-mBL, less than 5\% similarity to Burkitt lymphoma [11]; OxPhos, oxidative-phosphorylative pathway; PAP, pathway activation pattern; $W T$, wild-type; $P$ values refer to Fisher's exact test.

that full-length sequencing of SOCS1 must be done to determine the SOCS1 mutation status. Due to the shortness of this 636bp gene, however, this is easily feasible (also from DNA extracted from formalin fixed, paraffin embedded tumor tissue) and, therefore, should encourage independent validation in a larger and rituximab-treated cohort.

In summary, we have shown that SOCS1 mutation subtypes in DLBCL track with distinct gene expression signatures and predict divergent outcomes. Thereby the SOCS1 gene mutation status is a novel tumor-derived, single gene biomarker with prognostic relevance in DLBCL.

\section{MATERIAL AND METHODS}

\section{Regulatory Approval and Study Population.}

Ethics committees of all participating institutions approved the protocols of the network project "Molecular Mechanisms in Malignant Lymphoma" (MMML; see Supplemental Appendix 1). Descriptions of the MMML project protocols, histopathological review and classification according to WHO guidelines [30] have been part of prior publications with a different focus $[11,26,31,32]$. In this study the focus is SOCS1 mutation analysis in tumor samples from a consecutive cohort of well-characterized DLBCL patients. Table 1 lists the clinical characteristics of the cohort.

\section{PCR design and SOCS1 sequencing.}

The SOCS1 gene is divided in two exon regions: Exon 1 (length:104 bp) contains the 5' UTR (untranslated region) and exon 2 (length:1766 bp) contains part of the 5' UTR, the translation initiation site (position 705), the stop codon (position 1340=c.636), and the 3' UTR. Primers were M13-tailed (biomers.net, Ulm, Germany) and designed to capture a $761 \mathrm{bp}$ PCR fragment covering the complete open reading frame (636bp): exon2-forward primer 5'-CACCCCCGGACGCTATG and exon2-reverse primer 5'-CCACATGGTTCCAGGCAAGTA. After initial touchdown PCR, the amplification product was processed 
by agarose gel purification using the peqGOLD Gel Extraction Kit (peqlab, Erlangen, Germany). Sanger DNA sequencing employed the BigDye Terminator v3.1 Kit on a 3130 Genetic Analyzer (both ABI, Carlsbad, CA). Dye signals were translated by the $K B^{\mathrm{TM}}$ Base Caller Software and visualized using the Sequencing Analysis Software v5.4 (both ABI).

\section{SOCS1 sequence and mutation analysis.}

Forward and reverse sequences were manually analyzed by blasting the obtained sequence against the human SOCS1 sequence (ENST0000332029; SOCS1001; www.ensembl.org, last accessioned Oct $1^{\text {th }}, 2012$ ). After annotation of the nucleotide alterations, sequence information was translated into protein sequence (ExPASy translate tool, www.expasy.org/translate/, last accessed Oct $\left.1^{\text {th }} 2012\right)$. Alterations were mapped over the open reading frame as well as the known SOCS1 protein domains (Figure 1, Supplemental Figure 1) [18,20,33,34]. By plotting previously published mutated cases in a similar fashion (www.sanger.ac.uk/genetics/CGP/cosmic; last accessed Oct $1^{\text {th }}, 2012$; SOCS1: status Sept 13 $3^{\text {th }}, 2011$ ), we compared the distribution of sequence alterations (Figure 2). Additionally, the DNA sequence of mutated SOCS1 cases was used to analyze the targeting of the somatic hypermutation mechanism at specific hotspot motifs [28]. We used a DNA pattern search tool to identify somatic hypermutation hotspots (Gene Infinity LLC: http://www.geneinfinity.org/sms/sms_DNApatterns; last accessioned Oct $\left.1^{\text {th }}, 2012\right)$. Specifically, these preferred hotspots include $\mathrm{RGYW} / \mathrm{WRCY}$ (G:C is the mutable position; $\mathrm{R}=$ purine, $\mathrm{Y}=$ pyrimidine, and $\mathrm{W}=\mathrm{A} / \mathrm{T}$ ) [35], DGYW/WRCH (G:C is the mutable position; $\mathrm{D}=\mathrm{G} / \mathrm{T} / \mathrm{A}$; $\mathrm{H}=\mathrm{T} / \mathrm{C} / \mathrm{A}$ ) [36] and WA/TW (A:T is the mutable position) nucleotide pattern at both DNA strands [37]; see also supplement.

\section{Gene expression signatures.}

Prior characterization of cases employed in this study cohort included gene expression profiling on the Affymetrix U133A platform (Affymetrix, Santa Clara, CA, USA); data set GSE4475 is available at http://www.

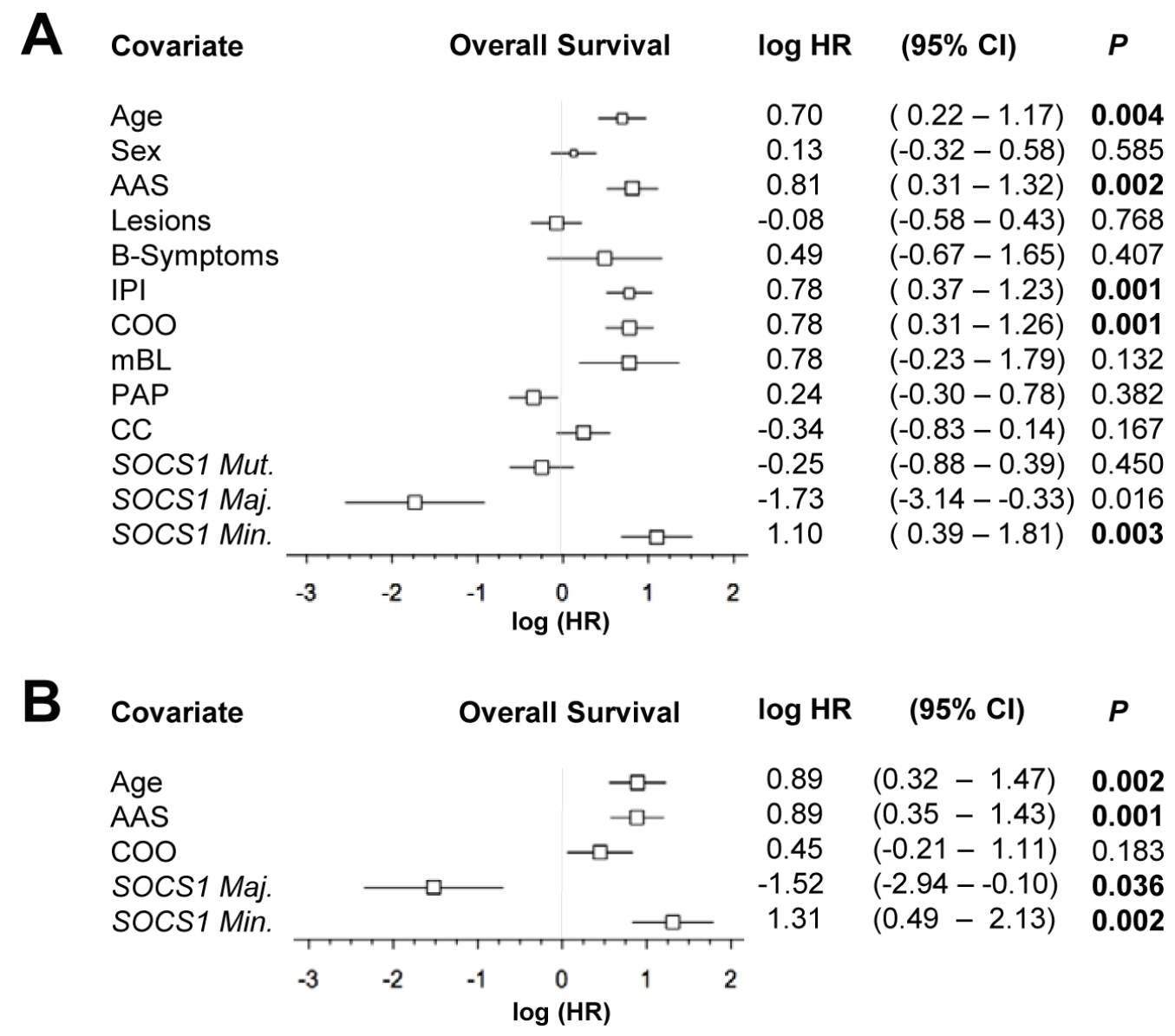

Figure 4: Forest plot of log hazard ratios (HR) for overall survival according to baseline clinical characteristics, assigned gene expression signatures and SOCS1 gene status as well as mutation types. A. Univariate and B. multivariate Cox proportional hazards regression models. Abbreviations: AAS, Ann Arbor Stage; IPI, international prognostic index; COO, cell-of-origin signature; mBL, molecular Burkitt signature; PAP, pathway activation pattern signature; $\mathrm{CC}$, consensus cluster signature; CI, confidence interval. Maj., major; Min.; minor; Mut., mutant. 
ncbi.nlm.nih.gov/geo/, last accessed Oct $1^{\text {th }}, 2012$. Briefly, four independently applied expression-based classifiers were attached to each case. These four classifiers were: the cell-of-origin signatures (COO) [10,38], the molecular Burkitt signatures (mBL) [11], the pathway activation pattern signatures (PAP) [12] and the consensus clustering signatures (CC) [13]. Nomenclature of the assigned signatures followed original publications: for the $\mathrm{COO}$ signature the subsets were $\mathrm{GCB}, \mathrm{ABC}$ and unclassified $[10,38]$; for the $\mathrm{mBL}$ signature the subsets were $\mathrm{mBL}$, non-mBL and intermediate [11]; for the pathway activation pattern signature [12] the subsets were BL-PAP, PAP-1, PAP-2, PAP-3, PAP-4, Mind-L, and for the CC signatures the subsets were oxidative phosphorylation (OxPhos), B-cell receptor/proliferation (BCR), host response (HR) [13]. When the original description of a classifier was based on another gene-expression platform than the one used herein (Affymetrix U133A), systematic differences were accounted for by applying appropriate adjustment algorithms [12,38].

Prior to the assignment of CC labels, study-specific effects (e.g., scanner generation, calibration, and platform) were adjusted in all models. Briefly, data from Monti et al. [13] were shifted and scaled to result in the same mean and variance as found across patients in the reference samples from Hummel et al. [11]. Subsequently, classification was performed by learning a linear 3-Class model with the nearest-shrunken centroid algorithm [39] on the data set of Monti et al. [13]. Finally this classifier was applied on the DLBCL samples from the MMML cohort, assigning the appropriate CC labels. Comparisons of each expressionbased signature and subtypes therein were performed as uni- and multivariate analysis (see below).

\section{Clinical features.}

To ascertain the representative nature of this study cohort, we applied established clinical criteria with respect to treatment: chemotherapeutic classes (CHOP-like, ALLlike), radiotherapy (yes/no), treatment response (complete remission, partial remission, stable disease, progressive disease) and relapse (yes/no).

\section{Statistical Analysis.}

Statistical analysis consisted of Fisher's exact test (association of mutation status with nominal factors in contingency tables) and t test (comparison of age). Due to the retrospective nature of this cohort, treatment strategies were not uniform [11]. Therefore, the performance of established prognostic factors was assessed in the study cohort (see Supplemental Figure 2). The KaplanMeier method was used to estimate overall survival and uni- as well as multivariate cox proportional hazards regression models were used to analyze survival data.
Given survival times, final life status (alive or dead) and one (univariate) or more (multivariate) covariates, the regression models produce a baseline survival curve and covariate coefficient estimates with their standard errors, $95 \%$ confidence intervals, and significance levels. The covariates included in these analyses were (parenthesis provide values set to 1$)$ : age $(\geq 60)$, LDH (upper limit of normal, >ULN), ECOG $(>1)$, Ann-Arbor stage (AAS; III/IV), extranodal involvement (EN; >1), B-symptoms (yes); morphology (immunoblastic, ib); COO signature (non-GCB); mBL signature (non-mBL); PAP signature (non-PAP1); CC signature (non-BCR); SOCS1 status (mutation positive); SOCS1 major and SOCS1 minor. Moreover, the international prognostic index (IPI) score was tested $(\geq 2)[40]$ and due to partial incompleteness of the basic data matrix for individual IPI characteristics in some patients, statistical testing was performed assuming the more pessimistic situation [i.e. a missing factor was set to "absent" (0); therefore some patients with IPI 0/1 may have higher IPI scores; Supplemental Figure 2E]. In univariate analyses, covariates were examined for their previously acknowledged prognostic impact, when applicable. In a second step, we combined factors demonstrating significance in univariate assessment in a multivariate analysis. Log hazard ratios are provided with the $95 \%$ confidence intervals (CI); significance was defined as $P<0.05$.

\section{ACKNOWLEDGMENTS}

We thank S. Jung, K. Dorsch, K. Hoffmann and K. Müller for excellent technical support. We furthermore thank U. Gerstenmaier for excellent support with gene analyses. We thank R. Marienfeld, J. Doherty, and T.F.E. Barth for thoughtful discussions. This work was supported by the Deutsche Krebshilfe (Network Project Molecular Mechanisms in Malignant Lymphoma, Bonn, Germany, grant 70-3173-Tr3). The Else-Kröner Fresenius Foundation supported JKL.

\section{Authorship Contributions}

PM conceived and designed the study; BS performed experiments; BS, JKL, CWK, OR, IM, PM analyzed mutations; CWK and SB assigned expressionbased classifiers; JKL, MK, ML, RS performed statistical analyses; LT provided the clinical data; BS, JKL, MK, RS, and PM wrote the manuscript.

\section{Conflicts of Interest Disclosures}

The authors declare no competing financial interests. 


\section{REFERENCE}

1. Coiffier B, Thieblemont C, Van Den Neste E, Lepeu G, Plantier I, Castaigne S, Lefort S, Marit G, Macro M, Sebban C, Belhadj K, Bordessoule D, Fermé C, Tilly H. Long-term outcome of patients in the LNH-98.5 trial, the first randomized study comparing rituximab-CHOP to standard CHOP chemotherapy in DLBCL patients: a study by the Groupe d'Etudes des Lymphomes de l'Adulte. Blood 2010;116:2040-2045.

2. Habermann TM, Weller EA, Morrison VA, Gascoyne RD, Cassileth PA, Cohn JB, Dakhil SR, Woda B, Fisher RI, Peterson BA, Horning SJ. Rituximab-CHOP versus CHOP alone or with maintenance rituximab in older patients with diffuse large B-cell lymphoma. J.Clin.Oncol. 2006;24:31213127.

3. Pfreundschuh M, Trümper L, Osterborg A, Pettengell R, Trneny M, Imrie K, Ma D, Gill D, Walewski J, Zinzani PL, Stahel R, Kvaloy S, Shpilberg O, Jaeger U, Hansen M, Lehtinen $\mathrm{T}$ et al. CHOP-like chemotherapy plus rituximab versus CHOP-like chemotherapy alone in young patients with good-prognosis diffuse large-B-cell lymphoma: a randomised controlled trial by the MabThera International Trial (MInT) Group. Lancet Oncol. 2006;7:379-391.

4. Pfreundschuh M, Schubert J, Ziepert M, Schmits R, Mohren M, Lengfelder E, Reiser M, Nickenig C, Clemens M, Peter N, Bokemeyer C, Eimermacher H, Ho A, Hoffmann M, Mertelsmann R, Trümper L et al. Six versus eight cycles of bi-weekly CHOP-14 with or without rituximab in elderly patients with aggressive CD20+ B-cell lymphomas: a randomised controlled trial (RICOVER-60). Lancet Oncol. 2008;9:105-116.

5. Gisselbrecht C, Glass B, Mounier N, Singh Gill D, Linch DC, Trneny M, Bosly A, Ketterer N, Shpilberg O, Hagberg H, Ma D, Brière J, Moskowitz CH, Schmitz N. Salvage regimens with autologous transplantation for relapsed large B-cell lymphoma in the rituximab era. J.Clin.Oncol. 2010;28:4184-4190.

6. Lossos IS, Morgensztern D. Prognostic biomarkers in diffuse large B-cell lymphoma. J.Clin.Oncol. 2006;24:9951007.

7. Sweetenham JW. Diffuse large B-cell lymphoma: risk stratification and management of relapsed disease. Hematology.Am.Soc.Hematol.Educ.Program. 2005252259 .

8. Choi WW, Weisenburger DD, Greiner TC, Piris MA, Banham AH, Delabie J, Braziel RM, Geng H, Iqbal J, Lenz G, Vose JM, Hans CP, Fu K, Smith LM, Li M, Liu Z, et al. A new immunostain algorithm classifies diffuse large B-cell lymphoma into molecular subtypes with high accuracy. Clin.Cancer Res. 2009;15:5494-5502.

9. Hans CP, Weisenburger DD, Greiner TC, Gascoyne RD, Delabie J, Ott G, Müller-Hermelink HK, Campo E, Braziel RM, Jaffe ES, Pan Z, Farinha P, Smith LM, Falini B, Banham AH, Rosenwald A et al. Confirmation of the molecular classification of diffuse large B-cell lymphoma by immunohistochemistry using a tissue microarray. Blood 2004; 103:275-282.

10. Alizadeh AA, Eisen MB, Davis RE, Ma C, Lossos IS, Rosenwald A, Boldrick JC, Sabet H, Tran T, Yu X, Powell JI, Yang L, Marti GE, Moore T, Hudson J Jr, Lu L et al. Distinct types of diffuse large B-cell lymphoma identified by gene expression profiling. Nature 2000;403:503-511.

11. Hummel M, Bentink S, Berger H, Klapper W, Wessendorf S, Barth TF, Bernd HW, Cogliatti SB, Dierlamm J, Feller AC, Hansmann ML, Haralambieva E, Harder L, Hasenclever D, Kühn M, Lenze D et al. A biologic definition of Burkitt's lymphoma from transcriptional and genomic profiling. N.Engl.J.Med. 2006;354:2419-2430.

12. Bentink S, Wessendorf S, Schwaenen C, Rosolowski M, Klapper W, Rosenwald A, Ott G, Banham AH, Berger H, Feller AC, Hansmann ML, Hasenclever D, Hummel M, Lenze D, Möller P, Stuerzenhofecker B et al. Pathway activation patterns in diffuse large B-cell lymphomas. Leukemia 2008;22:1746-1754.

13. Monti S, Savage KJ, Kutok JL, Feuerhake F, Kurtin P, Mihm M, Wu B, Pasqualucci L, Neuberg D, Aguiar RC, Dal Cin P, Ladd C, Pinkus GS, Salles G, Harris NL, Dalla-Favera $\mathrm{R}$ et al. Molecular profiling of diffuse large B-cell lymphoma identifies robust subtypes including one characterized by host inflammatory response. Blood 2005;105:1851-1861.

14. Rui L, Schmitz R, Ceribelli M, Staudt LM. Malignant pirates of the immune system. Nat.Immunol. 2011;12:933940.

15. Barth TF, Leithäuser F, Joos S, Bentz M, Möller P. Mediastinal (thymic) large B-cell lymphoma: where do we stand? Lancet Oncol. 2002;3:229-234.

16. Zinzani PL, Martelli M, Magagnoli M, Pescarmona E, Scaramucci L, Palombi F, Bendandi M, Martelli MP, Ascani S, Orcioni GF, Pileri SA, Mandelli F, Tura S. Treatment and clinical management of primary mediastinal large B-cell lymphoma with sclerosis: MACOP-B regimen and mediastinal radiotherapy monitored by (67)Gallium scan in 50 patients. Blood 1999;94:3289-3293.

17. Rosenwald A, Wright G, Chan WC, Connors JM, Campo E, Fisher RI, Gascoyne RD, Muller-Hermelink HK, Smeland EB, Giltnane JM, Hurt EM, Zhao H, Averett L, Yang L, Wilson WH, Jaffe ES et al. The use of molecular profiling to predict survival after chemotherapy for diffuse large-Bcell lymphoma. N.Engl.J.Med. 2002;346:1937-1947.

18. Melzner I, Bucur AJ, Brüderlein S, Dorsch K, Hasel C, Barth TF, Leithäuser, F, Möller P. Biallelic mutation of SOCS-1 impairs JAK2 degradation and sustains phosphoJAK2 action in the MedB-1 mediastinal lymphoma line. Blood 2005; 105:2535-2542.

19. Weniger MA, Melzner I, Menz CK, Wegener S, Bucur AJ, Dorsch K, Mattfeldt T, Barth TF, Möller P. Mutations of the tumor suppressor gene SOCS-1 in classical Hodgkin lymphoma are frequent and associated with nuclear 
phospho-STAT5 accumulation. Oncogene 2006;25:26792684.

20. Zhang J, Li H, Yu JP, Wang SE, Ren XB. Role of SOCS1 in tumor progression and therapeutic application. Int.J.Cancer 2012;130:1971-1980.

21. Zhang JG, Farley A, Nicholson SE, Willson TA, Zugaro LM, Simpson RJ, Moritz RL, Cary D, Richardson R, Hausmann G, Kile BJ, Kent SB, Alexander WS, Metcalf D, Hilton DJ, Nicola NA, et al. The conserved SOCS box motif in suppressors of cytokine signaling binds to elongins $\mathrm{B}$ and $\mathrm{C}$ and may couple bound proteins to proteasomal degradation. Proc.Natl.Acad.Sci.U.S.A 1999;96:2071-2076.

22. Melzner I, Weniger MA, Bucur AJ, Brüderlein S, Dorsch K, Hasel C, Leithäuser F, Ritz O, Dyer MJ, Barth TF, Möller P. Biallelic deletion within 16p13.13 including SOCS-1 in Karpas1106P mediastinal B-cell lymphoma line is associated with delayed degradation of JAK2 protein. Int.J.Cancer 2006;118:1941-1944.

23. Lohr JG, Stojanov P, Lawrence MS, Auclair D, Chapuy B, Sougnez C, Cruz-Gordillo P, Knoechel B, Asmann YW, Slager SL, Novak AJ, Dogan A, Ansell SM, Link BK, Zou $\mathrm{L}$, Gould J et al. Discovery and prioritization of somatic mutations in diffuse large B-cell lymphoma (DLBCL) by whole-exome sequencing. Proc.Natl.Acad.Sci.U.S.A 2012;109:3879-3884.

24. Capello D, Gloghini A, Baldanzi G, Martini M, Deambrogi C, Lucioni M, Piranda D, Famà R, Graziani A, Spina M, Tirelli U, Paulli M, Larocca LM, Gaidano G, Carbone A, Sinigaglia F. Alterations of negative regulators of cytokine signalling in immunodeficiency-related non-Hodgkin lymphoma. Hematol.Oncol. 2012

25. Mottok A, Renne C, Seifert M, Oppermann E, Bechstein W, Hansmann ML, Küppers R, Bräuninger A. Inactivating SOCS1 mutations are caused by aberrant somatic hypermutation and restricted to a subset of B-cell lymphoma entities. Blood 2009;114:4503-4506.

26. Klapper W, Kreuz M, Kohler CW, Burkhardt B, Szczepanowski M, Salaverria I, Hummel M, Loeffler M, Pellissery S, Woessmann W, Schwänen C, Trümper L, Wessendorf S, Spang R, Hasenclever D, Siebert R. Patient age at diagnosis is associated with the molecular characteristics of diffuse large B-cell lymphoma. Blood 2012;119:1882-1887.

27. Pasqualucci L, Trifonov V, Fabbri G, Ma J, Rossi D, Chiarenza A, Wells VA, Grunn A, Messina M, Elliot O, Chan J, Bhagat G, Chadburn A, Gaidano G, Mullighan CG, Rabadan $\mathrm{R}$ et al. Analysis of the coding genome of diffuse large B-cell lymphoma. Nat Genet. 2011;43:830-837.

28. Pasqualucci L, Neumeister P, Goossens T, Nanjangud G, Chaganti RS, Küppers R, Dalla-Favera R. Hypermutation of multiple proto-oncogenes in B-cell diffuse large-cell lymphomas. Nature 2001;412:341-346.

29. Khodabakhshi AH, Morin RD, Fejes AP, Mungall AJ, Mungall KL, Bolger-Munro M, Johnson NA, Connors JM, Gascoyne RD, Marra MA, Birol I, Jones SJ: Recurrent targets of aberrant somatic hypermutation in lymphoma. Oncotarget. 2012; 3: 1308-1319.

30. Swerdlow SH, Campo E, Harris NL, Jaffe ES, Pileri SA, Stein H, Thiele J, Vardiman JW. WHO Classification of Tumours, Volume 2.; 2008.

31. Klapper W, Szczepanowski M, Burkhardt B, Berger H, Rosolowski M, Bentink S, Schwaenen C, Wessendorf S, Spang R, Möller P, Hansmann ML, Bernd HW, Ott G, Hummel M, Stein H, Loeffler M et al. Molecular profiling of pediatric mature B-cell lymphoma treated in populationbased prospective clinical trials. Blood 2008;112:13741381.

32. Salaverria I, Philipp C, Oschlies I, Kohler CW, Kreuz M, Szczepanowski M, Burkhardt B, Trautmann H, Gesk S, Andrusiewicz M, Berger H, Fey M, Harder L, Hasenclever D, Hummel M, Loeffler $M$ et al. Translocations activating IRF4 identify a subtype of germinal center-derived B-cell lymphoma affecting predominantly children and young adults. Blood 2011;118:139-147.

33. De Sepulveda P, Okkenhaug K, Rose JL, Hawley RG, Dubreuil P, Rottapel R. Socs1 binds to multiple signalling proteins and suppresses steel factor-dependent proliferation. EMBO J. 1999;18:904-915.

34. Ilangumaran S, Rottapel R. Regulation of cytokine receptor signaling by SOCS1. Immunol.Rev. 2003;192:196-211.

35. Rogozin IB, Kolchanov NA. Somatic hypermutagenesis in immunoglobulin genes. II. Influence of neighbouring base sequences on mutagenesis. Biochim.Biophys.Acta 1992;1171:11-18.

36. Rogozin IB, Diaz M. Cutting edge: DGYW/WRCH is a better predictor of mutability at $\mathrm{G}: \mathrm{C}$ bases in $\mathrm{Ig}$ hypermutation than the widely accepted RGYW/WRCY motif and probably reflects a two-step activation-induced cytidine deaminase-triggered process. J.Immunol. 2004;172:3382-3384.

37. Rogozin IB, Pavlov YI, Bebenek K, Matsuda T, Kunkel TA. Somatic mutation hotspots correlate with DNA polymerase eta error spectrum. Nat.Immunol. 2001;2:530-536.

38. Wright G, Tan B, Rosenwald A, Hurt EH, Wiestner A, Staudt LM. A gene expression-based method to diagnose clinically distinct subgroups of diffuse large B cell lymphoma. Proc.Natl.Acad.Sci.U.S.A 2003;100:9991-9996.

39. Tibshirani R, Hastie T, Narasimhan B, Chu G. Diagnosis of multiple cancer types by shrunken centroids of gene expression. Proc.Natl.Acad.Sci.U.S.A 2002;99:6567-6572.

40. A predictive model for aggressive non-Hodgkin's lymphoma. The International Non-Hodgkin's Lymphoma Prognostic Factors Project. N.Engl.J.Med. 1993;329:987994. 